\title{
Early child care education: Evidence from the new law in Chile
}

Felipe Aravena Castillo, Marta Quiroga Lobos

Abstract: In the last decade, Chile has focused on early childhood education and care (ECEC) as a key opportunity to increase student-learning outcomes and decrease socio-economic inequalities. The creation of Chile's Under-Secretariat of ECEC in 2015 highlights the relevance of this educational stage. The purpose of this study is to analyse the new law (no. 20.835) on ECEC from the perspective of policy formulation. This study employs a discourse analysis that is based on a conceptual frame analysis of two concepts: relationships and roles. The findings indicate that the creation of the Superintendence of Education is an attempt at introducing accountability processes to ensure the quality of early childhood education. This is sustained by neoliberal policies, standardization and external influences. This study contributes to understandings of the relationship between stakeholders and school organizations and the degree of coherence and impact. Furthermore, the aim is to contribute to the international discussion surrounding educational policies beyond country-specific contexts.

Keywords: early childhood education and care (ECEC), policy analysis, education policy, Chile.

\section{Chilean Education System and Early Childhood Education and Care}

During the last three decades, neoliberal policies have been applied to the Chilean education context. The logical consequence of this is that the Chilean education system is being shaped by neoliberal policies in discourse and practice (Cavieres, 2011; Levin, 2011). Chile therefore has a competitive and selective education system that is highly segregated with strict so- 
cial stratification occurring from early childhood education and care (ECEC) through to tertiary education (Authors, 2016). This complex picture has forced the government to generate simultaneous and continuous education reforms and policies to improve the quality of education at the national level (Cavieres, 2011; Authors, 2017).

To reverse the effects of the social segregation in the education system, the Chilean state has created policies that seek to improve the quality of the education processes at all schooling levels. Following recommendations made to Chile by the OECD (2013), efforts to reduce the socio-economic gap in the education system are to be devoted to strengthening ECEC. Following this advice, Chile has increased its ECEC budget, devoting $0.8 \%$ of its GDP to this area ( $0.2 \%$ more than the OECD average). As the OECD states, there is a clear consensus over the growing importance of ECEC in Chile. Thus, in the last decade, Chile has focused on ECEC as an ideal stage at which student-learning outcomes can be improved and socio-economic inequalities reduced (Peralta, 2011; Pardo \& Woodrow, 2014).

This research analyses the impact of ECEC and particularly the creation of the Under-Secretariat on the Chilean education context. Simply put, the purpose of this study is to analyse the creation of the Chilean Under-Secretariat of Early Childhood Education (ECE). This necessarily involves the use of a structural approach employing a discourse analysis based on a conceptual frame derived from a law (no. 20.835). This study contributes to understandings of the relationship between stakeholders and school organizations and the degree of coherence and impact. We expect our research will enhance the quality of education by informing Chilean educational policies. Furthermore, we aim to contribute to the international discussion surrounding educational policies beyond country-specific contexts.

The paper begins with an exploration of ECEC policies in Chile. This section looks at the definition of ECEC in both the wider national context and through the specific lens of the Under-Secretariat's role in ECEC in Chile. Following this exploration a theoretical and conceptual framework is outlined, from within which two main concepts will be discussed: relationships and roles. Each of these is key to generating the discourse analysis based on the case. The next section problematizes, using the conceptual frame analysis, the possible implications for the Chilean ECEC in light of the creation of the Under-Secretariat. The final section reflects on the case, the education system, and improvements to ECEC in Chile. 


\section{Following the Legally Defined Chilean Pathway for Early Childhood Education and Care (ECEC)}

Chile has implemented a gradual, systemic and sectorial process of educational reforms (Cavieres, 2011). A clear example of how this process of change has occurred is the case of ECEC, which over a period of four years became part of the quality assurance system through the promulgation of a law that created the Under-Secretariat of ECE, the Superintendence of ECEC and modified various legal bodies (Law 20.835).

During the last decade, the first law enacted concerning ECEC was Law 20.248, known as the Preferential School Grant Act (2008). This recognized that vulnerable students need more financial resources to achieve learning standards and thus provided greater financial resources for Improvement Plans and educational goals to be achieved within a set time. This law only applies to children enrolled at the prekindergarten ( 3 - 4 years) and kinder (4 - 5 years) levels.

In 2009 the General Education Law (20.370) was promulgated, establishing the purposes of education and creating the basis of the quality assurance system. As far as ECEC is concerned, the quality assurance system is not compulsory (Article 25), and is therefore not a requirement for entry into primary schools (Article 26). It also establishes, in Article 28, that ECEC should promote integral child development, learning, knowledge, skills and attitudes.

The 2011 promulgation of Law 20.539 created the National System for Quality Assurance of ECEC, Secondary and Tertiary Education, and two new institutions: the Quality Agency in Education and the Superintendence of Education. The first is responsible for guiding, measuring and ranking school organizations according to their results, and the second, ensures that the financial resources provided by the state are used by stakeholders in such a way that contributes to school improvement. It is interesting to note that although the name of this legal body includes the abbreviation ECEC, the Article relating to it does not address the development of this educational level. Hence, in 2015 Law 20.835 was created precisely to fill this void.

Law 20.835 is composed of 17 articles. The first eleven are grouped under Title I, which establishes the creation of the Under-Secretariat of ECEC, and its relationship with the Superintendence of Education and the Quality 
Agency. Title II contains seven transitional articles establishing the powers of the President of the Republic to provide the new institutions with budgets and human resources. Therefore, Law 20.835 complements Law 20.529 in the sense that it addresses the development of ECEC as a key stage in education. From the description, it is clear that the law is very short, which has led to a lack of clarity in the meanings within documents as well as public confusion and dissemination of doubt (Ball, 2016).

\section{Policies in context: Conceptual framework}

Policies are key components in education systems. They are usually understood as concepts, phrases and serious statements (Henry, Lingard, Rizzvi \& Taylor, 2001). However, policies are fundamentally more complex than that because they are ideological and contain political facts with their own power and influence (Ball, 1998; Marshall, 2000; Ozga, 2000). From Ball's perspective, policies empower those claiming to speak with authority; they legitimize and initiate practices in the world, and they grant privilege to certain visions and interests (Ball, 1990, p.22). In this conceptualization of policy, strategic decisions are carried out based on the rationale stated. Furthermore, these strategic decisions tend to be more uniform and standardized across different education systems because of the globalization process (Ball, 1998; Ozga, Seddon \& Popkewitz, 2006).

From Foucault's perspective, policy is a set of linguistic facts linked together by syntactic rules of construction (2002). In the same vein, Gillies and Mifsud (2016) explain that policies aim to problematize the discourse by probing coherence, normative and inherent assumptions, and the rationale from which they originate. This brings complexity to the concept of policy, as policies are constructions that present problems and solutions based on contingency. It also warrants one to see policy texts as serious statements that provide thinking on how problems are solved through policies (Bacchi, 2009; Olssen, O’Neill \& Codd, 2004).

Mapping relationships contextualizes the geographic spaces in which policies are drawn up (Ball, 2016; Olssen, O'Neill \& Codd, 2004). It is essential to recognize the geographic context in order to fully analyse policies. Recognizing physical policy spaces means extending the limits of our geographical imagination. It also means attempting to grasp the way in which these spaces are joined up and re-worked in and through relationships (Ball, 2016). These spaces can produce emergent and unanticipated relationships between different actors involved in the formulation of policy. 
Such relationships can be analysed along two dimensions: intra-relations and inter-relations (Schriewer, 2014). For example, in this study we will analyse the type of relationship extant between the Under-Secretariat of ECEC, the Ministry of Education and school organizations. Therefore, intra and inter-relationships are key to understanding how policies are designed to respond to problems identified by multifaceted stakeholders

Jager and Maier's (2009) approach was selected as the methodology for the discourse analysis of Law 20.835: Creation of Under-Secretariat of ECEC. Using this approach the discourse analysis is conducted at different analytical stages in relation to the context, surface level of the text, rhetorical meanings, content and ideological statements and discourse position (p.55). It focuses the discourse policy analysis on one of these stages. In this study, we focus on the content and ideological statements. We consider serious statements in the text using a conceptual frame based on two main concepts: relationships and roles. This is part of a major framework rooted in a careful analysis of the concepts at play and the relationships between different stakeholders through discourse and practice (Gilles \& Mifsud, 2016).

Concepts differ depending on the actual context (Ball, 1998). Relationships and roles are used as conceptual frames for the policy analysis. These three concepts were selected because they explain a deep, global view of the conception of policy, especially in this specific Chilean case. In this study, it is important to recognize what type of relationships exist between different actors and how they are characterized through the policy narrative. This involves mapping relationships and analysing the network construct present within the policy.

In the context of policy formulation, it is necessary to identify if the roles are (re)shaped in a different way. Fundamentally, this means understanding the impact on the actors involved and how it creates possible new forms of power, authority and global forms of consideration, functions and responsibilities. Relationships and roles are essential components in the education context. Analysing components in this particular policy on ECEC allows us to see if, in the wider national context, it is possible to recognize common elements.

\section{Case study: Creation of Under-secretariat of Early Childhood Education in Chile}

A considerable volume of empirical and theoretical evidence indicates that high-quality ECEC increases young children's cognitive, social-emotional and 
academic outcomes (Connors \& Morris, 2014; Zaslow, Anderson, Redd, Wessel, Tarullo, \& Burchinal, 2010). These three elements are key factors in ensuring more productive, developed and safe learning environments for young children. In the Chilean case, these factors can be seen in the policies designed by the Ministry of Education-more specifically, in the creation of a new stakeholder in 2015: the Under-Secretariat of Early Childhood Education.

Article 18 of the General Law on Education in Chile no. 20.370 (2009) states:

"Early childhood education and care is the educational level that assists children from birth to the time they enter elementary school. Its objective is to favor systematically, promptly and pertinently the comprehensive development and relevant and significant learning in accordance with the curriculum determined as provided by this law."

The above definition indicates that ECEC is understood as a major part of education. In other words, ECEC is essential to the progressive development of young children. According to Peralta (2015), this definition reflects the historical conception that the Chilean early childhood education and care system employs: it starts from birth and its approach is comprehensive in nature (p.3). These features are the foundational principles of Chilean educational policies regarding ECEC.

ECEC in Chile has undergone recent and rapid change in the pursuit for quality. Pardo and Woodrow (2014) summarize the key changes which have occurred during the last decade in four parts: (i) the legal designation of early childhood education as the first level of the national education system; (ii) the establishment of a national curriculum framework for early childhood education that defines expected learning outcomes for children; (iii) the definition of quality standards for providers (those that are not mandatory and cover aspects of infrastructure, staff qualifications, the centre's education project and children to staff ratios); (iv) and the substantial expansion of access to education programmes for all children below 6-years old; by increasing the enrolment capacity in existing publicly funded centres serving 0-3 year-olds from low-income families, and the allocation of universal funds to guarantee free access to education for 4- and 5-year-olds attending publicly subsidized education centres (p.104). All of these changes are in line with the visibility and relevance obtained by ECEC in the Chilean context.

The Ministry of Education and different stakeholders, such as the National Board of Nursery Schools (In Spanish: Junta Nacional de Jardines Infan- 
tiles, JUNJI), Integra Foundation and school organizations, have to be able to read these changes and interpret how and why these new changes impact on the Chilean education system. In this regard, the Law (no. 20.835) on the Creation of the Under-Secretariat of ECEC was enacted in 2015. This new stakeholder is a body that acts directly in collaboration with the Ministry of Education in the promotion, development, general organization and coordination of quality ECEC for the integral development of children from birth until entry into basic education (p.1). Thus, this new stakeholder supports and works with the Ministry of Education.

The law set out the two main functions of the Under-Secretariat, which are to:

a) propose to the Minister of Education the policies, plans and programs in matters relating to ECEC and, b) propose to the Ministry of Education the legal and regulatory norms that regulate ECEC, in particular those related to the requirements for obtaining official recognition of the State (Article 3).

The Under-Secretariat also has responsibility for elaborating the technical criteria as follows:

1) To elaborate and propose the technical criteria, according to the high specialty of the level of ECEC, that orient the supervisory function of the Superintendence regarding of the establishments that impart it. 2) To propose to the Superintendent the administrative interpretation of the educational regulations applicable to the establishments that teach ECEC. 3) To propose to the Superintendent general application instructions for the sector subject to its competence. 4) Produce indexes, statistics and studies related to the Nursery Education system (article 7).

\section{Relationships in case study: Creation of under-secretariat of early childhood education in Chile}

According to Fielding (2006), the act of seeking to improve education systems leads to personal relationships and functional relationships forming among stakeholders. Functional relationships are typically shaped by the desire to achieve particular goals. In contrast, personal relationships exist to provide people with emotional support, where it is crucial to be open and honest with others regarding the different sides of our personality. Fielding (2006) points out that even though functional and personal relationships are interrelated, they do not have the same relevance. This is because functional relationships not only benefit personal relationships, but they also 
involve power and influence. Consequently, these types of relationships are intrinsically complex, tensional and multidimensional.

The association between functional relationships and personal relationships requires trust between stakeholders in order to build a space where understanding is the interaction centre between "myself" and "the other" (Fielding, 2006). From this perspective, policies need to generate functional relationships that encourage trustworthy relationships within the educational system. In this sense, it is important to analyse how policies can build positive relationships between all members of the education system. As such, it is necessary to understand functional and personal relationships to achieve successful learning goals at different levels.

Policies lead to the restructuring, redistribution, and division of power relations (Foucault, 1981: 94). In order to explore the change in roles and functions within the Ministry of Education and the kindergartens, two analyses will be carried out. The first is based on the organization chart of the Ministry of Education (Mineduc, 2017), and the second on the implementation of the basic school insurance system. These charts indicate the main concerns, tensions and possible projections of nursery schools.

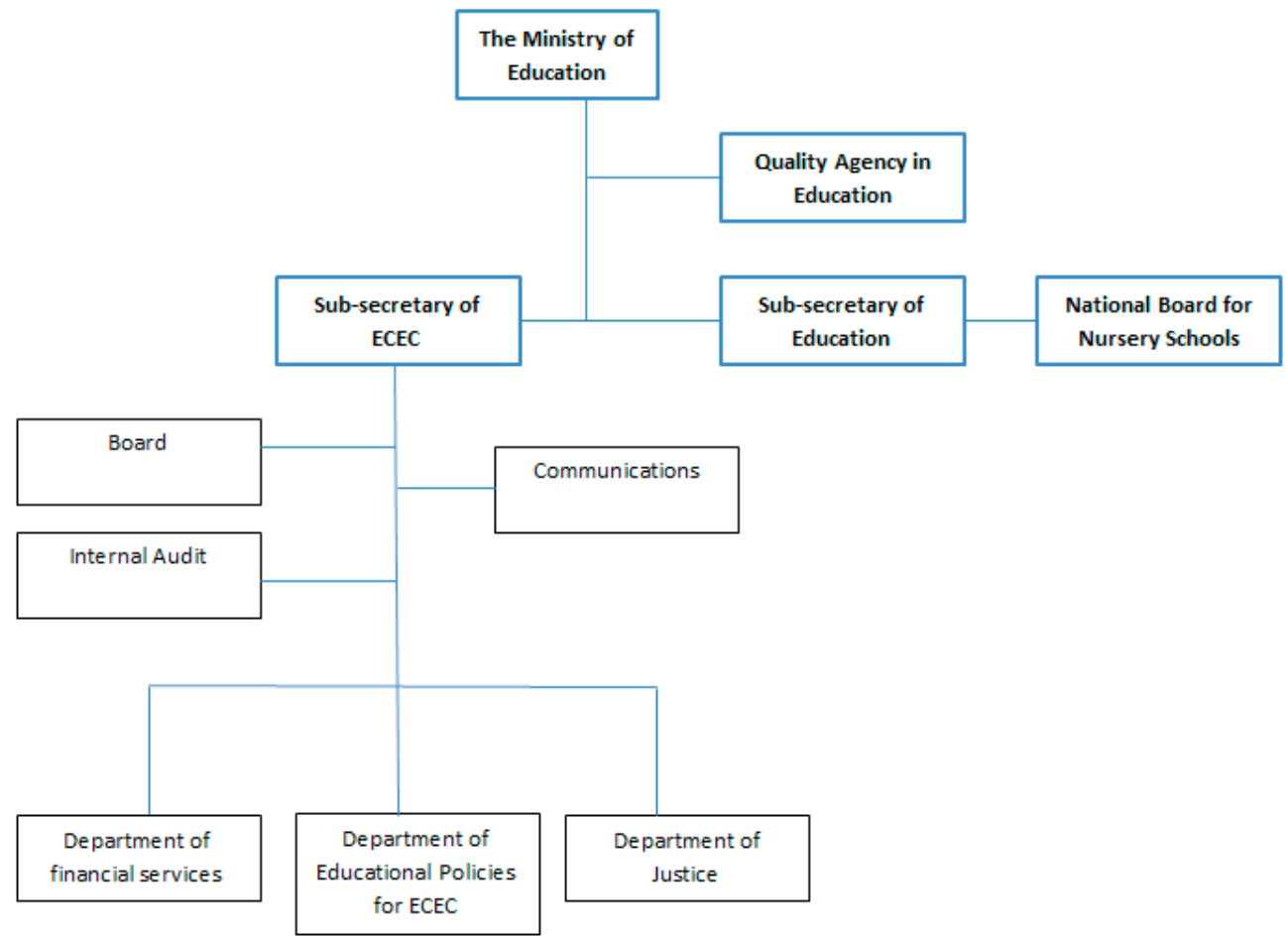

Figure 1: Organization of ECEC in Chile 
The following chart shows the different departments, some of their functional relationships and the position of the recently created Under-Secretariat of ECE, which is at the same hierarchical level as the Under-Secretariat of Education. This is a clear indicator of the importance the legislator ascribes to ECE.

Article 11 (Law 20.835) specifies that a councillor specializing in ECEC should be appointed to the Quality Agency in Education (upper right of the organization chart). The creation of this new position on the Quality Agency Council aims to ensure the adequacy of the quality criteria for organizations in ECEC. There is doubt as to the nature of the relationship between the Department of Education Policies for ECEC (left side of the organization chart) and the Under-Secretariat in Education for ECEC. The main question is why if the new role of Under-Secretary was created so that all ECEC issues are subsumed under one body is there still an autonomous body with responsibility for ECEC education policies. This results in a complex relationship, as can be seen in the fragmented relationship in the chart, which clearly shows the two roles overlapping.

The definition of roles at the Quality Agency in Education and the division of education policies are key aspects that validate the quality criteria issuing from the specialized agency and its position within the quality logic of the entire education system. In short, this legal text establishes a new relationship of power within the Ministry of Education, pointing to "the complexity of relationships between political intentions, texts, interpretations and reactions" (Ball, 2016, p.25). In practice, such complexity may involve interpretations and reinterpretations of functional relationships rather than personal relationships.

The same chart shows that the National Board of Nursery Schools (JUNJI) is an agency directly under the Ministry of Education and, according to Article 4 of Title II of Law 20.835, it has had its supervisory powers and ability to grant permits to kindergartens transferred to the Superintendence of Education. However, its position has not changed in the organization chart. For this reason it is important to ask why the National Board of Nursery Schools does not fall within the remit of the Under-Secretariat, since it directly manages 435 kindergartens as well as another 1,677 via the transfer of funds and 468 alternative kindergartens. In structural terms, this policy does not support personal relationships between these stakeholders.

Along with the above, we consider that it would have been beneficial to 
have left the JUNJI within the remit of the Under-Secretariat of ECEC. The JUNJI could have provided the Under-Secretariat with practical advice, considering its experience in teaching young children. Consequently, not transferring the JUNJI to the Under-Secretariat and only removing the official recognition of kindergartens may provoke power disputes between the Under-Secretary (a political appointment) and the head of JUNJI (technical/ political appointment). This will affect the quality of personal and functional relationships and hamper improvements to the system. More specifically, this policy will problematize relationships between the Under-Secretariat of Education and the Under-Secretariat for ECEC, creating practical difficulties with the implementation of policy, especially in the case of externally defined quality practices for JUNJI. This, when considered in relation to a highly unionized organization such as that of JUNJI officials, could become an additional political complication for the Under-Secretariat. For this reason, the change of relationships should not only be subjected to an analysis of the constraints, but also to a fundamental analysis of the possibilities of achieving the global and local results of the policy (Ball, 2006).

The legal modifications described in the organizational chart show that the new bodies are clearly differentiated and atomized in regard to their technical tasks. This new organization (re)shapes the relationships subsumed in two large pre-existing structures: the Quality Agency in Education and Superintendence of Education. These modifications will bring about a functional change in terms of relationships, but not necessarily in terms of institutional practices and personal relationships, which will need a period of role re-definition especially in the relationships that establish the headquarters of the different units. At the macro level, the success of some policies is not determined by the literal wording of laws and statutes, but is generated as a result of social disputes and the functionality of personal relationships (Offe, 1984).

The provisions of this law, as explained above, are concurrent with other legal changes. Its provisions mainly concern the quality and equity of education services for children, ensuring early schooling for children-especially the most vulnerable, which is concurrent with quality learning policies. From this perspective, early care practices for schooling have been abandoned, forcing nursery schools to develop care and teaching practices that allow students to successfully integrate into secondary education. This new development introduces complexity into the functional and personal relationships and the way in which they can be structured. 


\section{Roles in case study: Creation of under-secretariat of early childhood education in Chile}

Relationships are determined by their roles as symbolic products of social interactions (DiMaggio, 1997). Therefore, it is important to recognise that roles and relationships are interrelated. They are part of collective experiences and learning that emerge from a common cultural background. According to DiMaggio (1997) individuals experience culture as disparate bits of information and as schematic structures that organize that information (p.1). So, roles are crucial parts of shared mental models (Ball, 2009). Therefore, they are not just attitudes or dispositions; they are fundamental products of cognitive processes. This adds more complexity to the situation because individual codes depend on the rules of social systems, which in this case are proposed by the Ministry of education. It emphasises a symbolic approach in which roles are constantly subject to dialectic dimensions: the Superintendence of Education and the Under-Secretariat of ECEC.

The policy reiterates that the role of parents is key. It states that the role of parents and guardians (Article 2) and early schooling are two essential aspects set out in Law 20.835 and concurrent with the principles stipulated in the General Education Law (Article 3). The role of parents is explained in terms of their rights and duties. They are given the status of:

Community members, with a key role to participate in the formulation of the educational project, to organize in the parents' center, to participate in Technical-pedagogical decisions through the school councils, to be informed about the implementation and progress of the school improvement plan.

The law clearly emphasizes that parents have an important role to play in school organizations in ECEC. Their role in early childhood development is even clearer than that of the school. Parents are conceived of as information users and decision makers tasked with making changes to kindergarten for their children. In the General Education Law, this parental responsibility is explicited laid out as a right and a duty. This complicates the situation because the role of the school is categorized as complementary to that of the parent. This is certainly true, but can be misunderstood because schools produce learning and create spaces for interaction, while parents cannot. The other important role referred to in the policy is that performed by the Quality Agency in Education.

This stakeholder has responsibility for evaluating the performance of 
schools at all education levels. Based on the legislative framework derived from a comprehensive evaluation, the role is defined as the implementer of the evaluation and classification of primary and secondary educational institutions. The evaluation factors in the results of the standardized national tests, so good results are associated with a better or very good school classification. This model, according to Carrasco and Urrejola (2017), has not installed a comprehensive evaluation system, but rather a standards-based reform in which standardized tests predominate, impoverishing the curriculum and negatively affecting teachers, management teams and the school in general. This shows a disconnect between the law as textual discourse and its implementation in practice, producing what Rizvi \& Kemmis (1987) called "interpretations of interpretations," which manipulate the true meaning.

Only the roles of parents and the Quality Agency in Education are clearly defined and delimited. This is because they are considered part of the policy of assurance in ECEC based on standards and student performances. However, this purpose will not stimulate collaboration and will negatively affect preschool teachers. The result of this policy will be assimilation based on standards in ECEC. Riseborough (1992) referred to this type of consequence as subterranean life or secondary adjustments in response to unexpected policy consequences.

\section{Conclusions and Final Thoughts}

Undoubtedly, the creation of a specific institutional framework for ECEC reinforces the importance of learning from the earliest of ages and its impact on the cognitive, affective and motor development of students. This is clear progression for the quality of education in Chile.

The creation of the Under-Secretariat of Education for ECEC allows for different initiatives and recognizes their specificity. Thus, it is important that this status be given to ECEC in Chile as it comes to redesign roles and relationships. However, the weak link in terms of the functional relationships with the other divisions within the Ministry of Education and the definition of collaborator in the design of present policy may present obstacles.

The search for coherence in the quality assurance system may end up drowning out the differentiation and specificity within ECEC, preventing the Under-Secretariat from being able to visualize its particularities and implement ad hoc processes of quality assurance. If this occurs, the sus- 
tainability and incidence of specific policies could be questioned and shortterm adjustments to its regulation may take place, either to strengthen it or to weaken its position within the Ministry of Education. The question is whether the logic of high impact accountability (measured by standardized tests) is applicable to nursery schools and will improve children's learning.

In conclusion, this policy introduces external coherence between different stakeholders. This can be clearly observed in terms of the assurance of the quality of education. However, this is not the case with the roles and relationships because a key concept has not been defined and set out. Schools are understood as observers rather than active participants that use policies and programs from top to bottom. This concept of the school presents a key risk to ECEC because the school is not defined as an active constructor of reality. Despite its flaws, this policy enables the emergence of a positive internal space for schools to have the freedom and autonomy to shape roles and relationships. The main question concerns the school's potential to shape other roles not defined by the policy.

\section{References}

Aravena, F., \& Quiroga, M. (2016). Neoliberalism and education on an international perspective: Chile as perfect scenario. Bulgarian Journal of Science \& Education Policy, 10 (1), 1-21.

Bacchi, C. (2009). Analysing policy: What's the problem represented to be? French Forest: Pearson.

Ball, S. (1998). Big policies/small world: An introduction to international perspectives in education policy. Comparative Education, 34 (2), 119-130.

Ball, S. (2009). Privatising education, privatising education policy, privatising educational research: Network governance and the 'competition state, Journal of Education Policy, 24 (1), 83-99.

Ball, S. (2016). Following policy: Networks, network ethnography and education policy mobilities, Journal of Education Policy, 31 (5), 1-18.

Carrasco, A. Y, \& Urrejola, A. (2017). La agencia de calidad de la educación: ¿Una política de evaluación integral? Revista Educación, Politica y Sociedad, 2 (1), 8-26.

Cavieres, E.A. (2011). The class and culture-based exclusion of the Chilean neoliberal educational reform. Educational Studies, 47 (2), 111-132.

Connors, M., \& Morris, P. (2014). Comparing state policy approaches to early care and education quality: A multidimensional assessment of quality rating and improvement systems and child care licensing regulations. Early Childhood Research Quarterly 30, 266-279.

DiMaggio, P. (1997). Culture and cognition. American review of Sociology, 23, 26387.

Fielding, M. (2006). Leadership, personalization and high performance schooling: 
Naming the new totalitarianism. School Leadership and Management, 26 (4), 347369.

Foucault, M. (2002). The archaeology of knowledge. London: Routledge.

Gillies, D., \& Mifsud, D. (2016). Policy in transition: The emergence of tackling early school leaving as EU policy priority, Journal of Education Policy, 31 (6), 819-832.

Henry, M., Lingard, B., Rizzvi, F., \& Taylor, S. (2001). The OECD, Globalisation and Education Policy. London: Pergamon.

Jager, S., \& Maier, F. (2009). Theoretical and methodological aspects of Foucauldian critical discourse analysis and dispositive analysis. In R. Wodak, \& M. Meyer (Eds.), Methods of critical discourse analysis (pp. 34-61). London: Sage.

Levin, B. (2011). Chile, Latin America, and inequality in education. Phi, Delta, Kappan, 93 (2), 74-75.

Law (2015). Ley 20.835. Retrieved 21st april 2017 http://www.leychile.cl/Navegar?idNorma $=1077041$

Marshall, C. (2000). Policy discourse analysis: negotiating gender equity. Journal of Education Policy, 15 (2), 125-156.

Ministry of Education, Chile. (2017). Organigrama del Ministerio de educación de Chile. Retrieved 21st april 2017 http://portales.mineduc.cl/transparencia/organica.html

Ministry of Education, Chile. (2014). Antecedentes generales del nivel de educación parvularia en Chile. Retrieved 21st april 2017 https://www.camara.cl/pdf.aspx?pr$\mathrm{mID}=26576 \& \mathrm{prmTIPO}=\mathrm{DOCUMENTOCOMISION}$

OECD. (2013). Education at a glance: Key facts for Chile in education at a glance 2014. Paris: OECD.

Offe, C. (1984). Problemas estruturais do estado capitalista. Rio de Janeiro: Tempo Brasileiro.

Olssen, M., O’Neill, A., \& Codd, J. (2004). Education policy, globalization, citizenship and democracy. London: Sage.

Ozga, J. (2000) Policy research in educational settings. Buckingham: Open University Press.

Ozga, J., Seddon, T., \& Popkewitz, T. (2006). Education research and policy, steering the knowledge economy. London: Routledge.

Pardo, M., \& Woodrow, C. (2014). Improving the quality of early childhood education in Chile: Tensions between public policy and teacher discourses. Over the schoolarisation of early childhood education. International Journal of Early Childhood, 46 (1), 101-115.

Peralta, M. (2011). Early childhood education and public care policies in Chile: A historical perspective to analyse the present. International Journal of Child Care and Education, 5 (1), 17-27.

Riseborough, G. (1992). Primary headship, state policy and the challenge of the 1990s: An exceptional story that disproves total hegemonic rule. Journal of Education Policy, 8 (2), 155-173.

Rizvi, F., \& Kemmis, S. (1987). Dilemmas of reform: An overview of issues and achievements of the Participation and Equity Program in Victorian schools 1984-1986. Deakin Institute for Studies in Education: Deakin University.

Schriewer, J. (2014). Neither orthodoxy nor randomness: Differing logics of con- 
ducting comparative and international studies in education. Comparative Education, 50 (1), 84-101.

Zaslow, M., Anderson, R., Redd, Z., Wessel, J., Tarullo, L., \& Burchinal, M. (2010). Quality dosage, thresholds, and features in early childhood settings: A review of the literature (OPRE 2011-5). Washington, DC: Office of Planning, Research and Evaluation, Administration for Children and Families, U.S. Department of Health and Human Services.

\section{Authors:}

Felipe Aravena Castillo, professor

Pontificia Universidad Católica de Valparaíso

School of Education

Chile

Email: felipe.aravena@pucv.cl

Marta Quiroga Lobos, professor

Pontificia Universidad Católica de Valparaíso

School of Education

Chile

Email: marta.quiroga@pucv.cl 